Document downloaded from:

http://hdl.handle.net/10251/157209

This paper must be cited as:

Tolardo, V.; García-Ballesteros, S.; Santos-Juanes Jordá, L.; Vercher Pérez, RF.; Amat Payá, AM.; Arqués Sanz, A.; Laurenti, E. (2019). Pentachlorophenol Removal from Water by Soybean Peroxidase and Iron(II) Salts Concerted Action. Water Air \& Soil Pollution. 230(6):1-8. https://doi.org/10.1007/s11270-019-4189-7

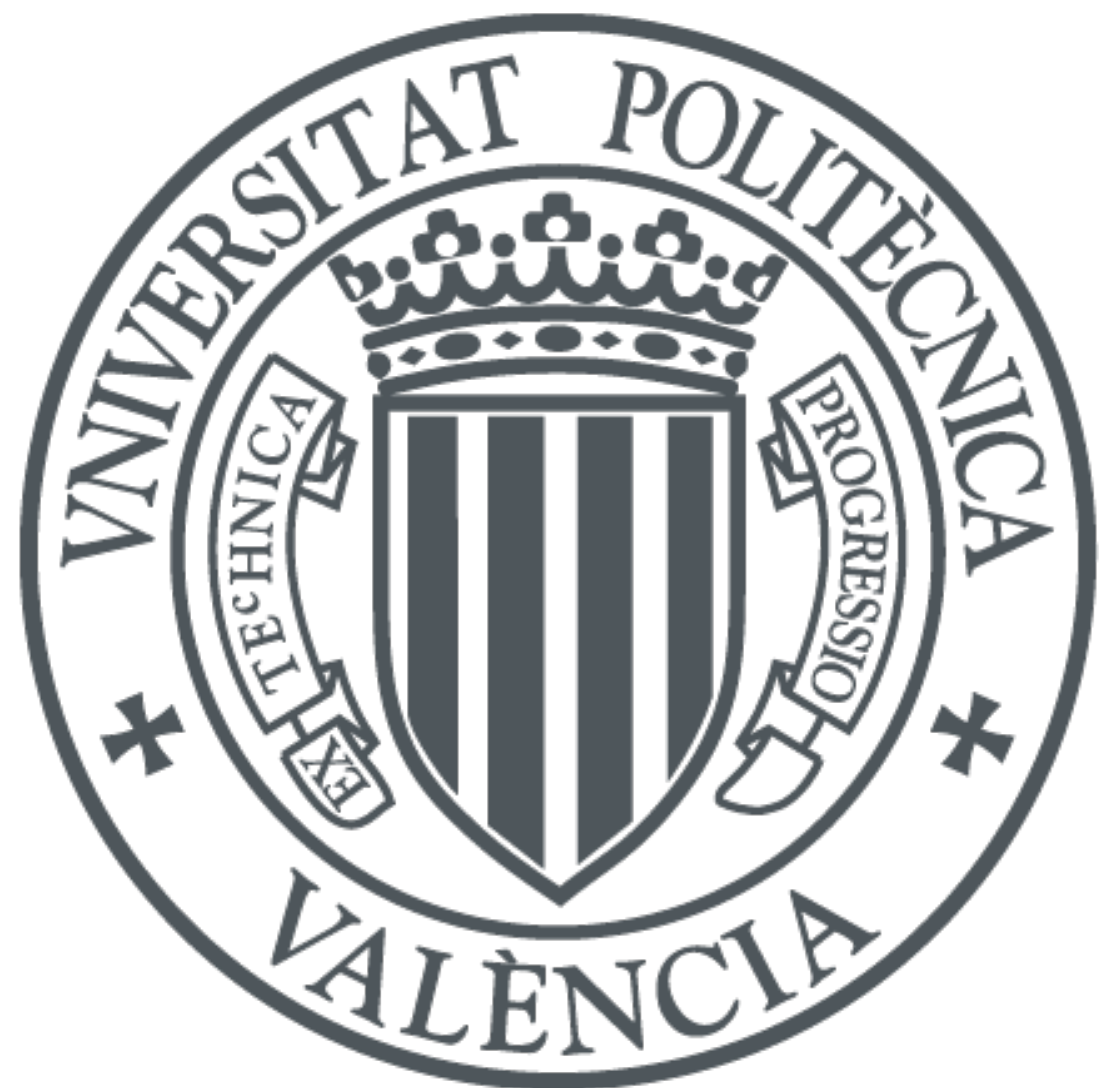

The final publication is available at

https://doi.org/10.1007/s11270-019-4189-7

Copyright Springer-Verlag

Additional Information 


\section{Pentachlorophenol removal from water by Soybean peroxidase and iron(II) salts concerted action}

Valentina Tolardo ${ }^{\mathrm{a}, 1}$, Sara García-Ballesteros ${ }^{\mathrm{b}}$, Lucas Santos-Juanes ${ }^{\mathrm{b}}$, Rosa Vercher ${ }^{\mathrm{b}}$, Ana M. Amat ${ }^{\mathrm{b}}$, Antonio Arques ${ }^{\mathrm{b}}$, Enzo Laurenti a,*

${ }^{a}$ Department of Chemistry, Università di Torino, Via P. Giuria 7, 10125 Torino, Italy.

${ }^{\mathrm{b}}$ Grupo Procesos de Oxidación Avanzada, Campus de Alcoy, Universitat Politècnica de València, Spain.

${ }^{1}$ Present address: Smart Materials, Istituto Italiano di Tecnologia, Via Morego, 30, 16163 Genova, Italy.

* Corresponding author: enzo.laurenti@unito.it, phone: +390116707951, fax: +39 0116707855, ORCID: 0000-0001-7363-4002

\section{Abstract}

Soybean peroxidase (SBP) has been employed for the treatment of aqueous solutions containing pentachlorophenol (PCP) in the presence of hydrogen peroxide at $\mathrm{pH}$ range 5-7. Reaction carried out with 1 $\mathrm{mg} / \mathrm{L}$ of PCP, $4 \mathrm{mg} / \mathrm{L}$ of $\mathrm{H}_{2} \mathrm{O}_{2}$ and $1.3 \times 10^{-9} \mathrm{M}$ of SBP, showed a fast initial elimination of PCP (ca. $30 \%$ in $20 \mathrm{~min}$ ), but the reaction does not go beyond the removal of 50\% of the initial concentration of PCP. Modification in SBP and PCP amounts did not change the reaction profile and higher amounts of $\mathrm{H}_{2} \mathrm{O}_{2}$ were detrimental for the reaction. Addition of $\mathrm{Fe}(\mathrm{II})$ to the system resulted in an acceleration of the process to reach nearly complete PCP removal at $\mathrm{pH} 5$ or 6; this is more probably due to a synergetic effect of the enzymatic process and Fenton reaction. However, experiments developed in tap water resulted in a lower PCP elimination, but this inconvenience can be partly overcome by leaving the tap water overnight in an open vessel before reaction.

Keywords: soybean peroxidase; Fenton; pentachlorophenol; hydrogen peroxide; wastewater; iron

\section{Acknowledgments}

The authors want to thank the financial support of the European Union (PIRSES-GA-2010-269128, EnvironBOS) and Spanish Ministerio de Educación y Ciencia (CTQ2015-69832-C4-4-R). Sara GarcíaBallesteros would like to thank Spanish Ministerio de Economía y Competitividad for her fellowship (BES- 
2013-066201). We also want to acknowledge Davide Mainero from Acea Pinerolese for his collaboration in this research. 


\section{Introduction}

Chlorophenols are a group of pollutants that constitute a serious environmental and health concern (Li 2018; Zheng et al. 2012). Despite their natural formation in soil (Hoekstra et al. 1999) or in marine environment (Ballschmiter 2003), the main contribution to the presence of these substances in the environment is due to anthropogenic activities, since they are widely used as bactericides, insecticides, herbicides, fungicides or wood preservatives, and as intermediates in the production of dyes and pharmaceuticals (Czaplicka 2004; Olaniran and Igbinosa 2011; Tsai 2013; Verbrugge et al. 2018). In addition, natural microbial degradation of herbicides and pesticides results in a worldwide release of highly toxic derivatives in the environment. Although chlorophenols can be in turn be degraded by aerobic and anaerobic microorganism, their persistence and the toxicity of degradation products led to the development of new methods to obtain more effective and rapid removal of these substances from the environment.

Since chlorophenols can also inhibit the efficiency of activated sludge bacteria (Essam et al. 2007), the development of more efficient wastewater treatment processes is continuously proposed. Some of these new methods are based on the use of isolated enzymes. According to their high specificity, tailored processes can be designed for the removal of groups of pollutants (Durán and Esposito 2000). Moreover, the use of isolated enzymes instead of whole microorganisms maintains enzyme concentration independent from bacterial growth rates and permits an easier storage (Caza et al. 1999).

Some oxidoreductases (i.e. ligninases, laccases, peroxidases, or tyrosinases) isolated from plants and fungi were tested for this kind of treatment as they are able to transform phenols (including chlorophenols) into less hazardous compounds (Naghdi et al. 2018; Qayyum et al. 2009). In particular, the use of peroxidases is justified by their high oxidative potential and relatively low selectivity, which permits to catalyse the peroxide-mediated oxidation of a wide number of compounds (Passardi et al. 2005). In this context, a stable and efficient peroxidase isolated from soybean (Glycine max, L.) seed hulls was proposed for the application in wastewater remediation, showing its ability to degrade both aromatic compounds and synthetic dyes (Caza et al. 1999; Marchis et al. 2011; Steevensz et al. 2014).

On the other hand chemical processes like electrochemical reduction (Sun et al. 2015), hydrodechlorination by hydrogen peroxide (Muñoz et al. 2013) and advanced oxidation processes (AOP) (Karci 2014; Pera-Titus et al. 2004; Sharma et al. 2013) have been employed for the removal of chlorophenols. In particular, 
emerging approaches for wastewater treatment involve, in most cases, the coupling of biological methods with AOPs (Oller et al. 2011; Sarria et al. 2002). For instance, a combined use of ozonation and microbiological degradation has been reported for the removal of 4-chloro and 2.4-dichlorophenol (GarciaPeña et al. 2012).

The Fenton and photo-Fenton process can be found among the AOP that have been more widely used (Babuponnusami and Muthukumar 2014). They use the ability of iron salts to decompose hydrogen peroxide into more reactive species. However, acidic $\mathrm{pH}$ (ca. 2.8) is required to avoid iron inactivation and strategies are now being developed to work at mild conditions (Lucas Santos-Juanes et al. 2017); some of them involve coupling treatments, such as combining the reducing ability of zero-valent iron (ZVI) to induce changes in the structure of the molecules and, at the same time, using ZVI as a source of iron for a Fenton process (Donadelli et al. 2018; L. Santos-Juanes et al. 2017). Starting from these data, the possibility of coupling Fenton with SBP seems particularly interesting, as they both employ $\mathrm{H}_{2} \mathrm{O}_{2}$ as oxidising agent and this strategy might combine the mild $\mathrm{pH}$ optimal values of SBP activity, in the range 5-7 (Caza et al. 1999; Marchis et al. 2012), with the higher oxidative efficiency of Fenton, even at low amounts of iron. As far as we know, this approach remains unexplored; therefore in this paper we investigated the potential use of the system SBP/hydrogen peroxide in the presence of iron(II) as a method for wastewater treatment, using pentachlorophenol (PCP) as model compound.

\section{Material and methods}

\section{Chemical reagents}

Pentachlorophenol (PCP) was purchased from Sigma Aldrich. Hydrogen peroxide (30\% v/v) and ferrous sulphate were supplied by Panreac. Water employed in the experiments was Milli-Q grade, except for those run with tap water. All reagents were at high purity grade and used as received.

\section{Soybean peroxidase isolation and purification}

Soybean peroxidase (SBP) was extracted from the hulls of soybean seeds, kindly furnished by Prof. D. Sacco (Department of Agricultural, Forest and Food Sciences, Università di Torino, Italy). After the peeling of seeds, the hulls had been stored at $-12{ }^{\circ} \mathrm{C}$ until use, then SBP was extracted and purified by a process based 
on a previously published method (Calza et al. 2016). One hundred grams of soybean hulls were ground in a mortar, added to $600 \mathrm{~mL}$ of phosphate buffer $(0.025 \mathrm{M}, \mathrm{pH} 7)$ and left under stirring for two hours at room temperature. Then, the hulls were separated from the solution by filtration with cotton gauze and the filtrate was centrifuged for $15 \mathrm{~min}$ at $4000 \mathrm{rpm}$. After the centrifugation, the supernatant was separated and tested for peroxidase activity by the $\mathrm{H}_{2} \mathrm{O}_{2} / \mathrm{DMAB}-\mathrm{MBTH}$ system: $10 \mu \mathrm{L}$ of SBP containing supernatant were added to $3 \mathrm{~mL}$ of a solution containing 3-(dimethylamino)benzoic acid (DMAB, $5 \times 10^{-4} \mathrm{M}$ ), 3-methyl-2benzothiazolinonehydrazone (MBTH, $\left.2 \times 10^{-3} \mathrm{M}\right)$ and $\mathrm{H}_{2} \mathrm{O}_{2}\left(1 \times 10^{-2} \mathrm{M}\right)$ in acetate buffer $0.1 \mathrm{M} \mathrm{pH} 5.4$. The enzymatic activity was measured by following the increase of absorbance at $590 \mathrm{~nm}$ of the reaction product (Ngo and Lenhoff 1980).

The treatment of the hulls with phosphate buffer was repeated five times with decreasing buffer volume (600 $\mathrm{mL}, 500 \mathrm{~mL}, 400 \mathrm{~mL}$ ) until the resulting solution gave a negative response to the activity test. Then, SBP containing solutions were collected with a Vivaspin 20 (Sartorius, 10000 MWCO) tangential filter in a centrifuge (4000 rpm, $30 \mathrm{~min}$ ). Successively the proteins were precipitated by addition of ammonium sulphate until saturation (53 g in $100 \mathrm{~mL}$ ), and the mixture was left under stirring for one night at $4{ }^{\circ} \mathrm{C}$. The precipitate was centrifuged for $20 \mathrm{~min}$ at $4000 \mathrm{rpm}$ and dissolved in $250 \mathrm{~mL}$ of phosphate buffer $(0.025$ $\mathrm{M}, \mathrm{pH}$ 7). The resulting solution was then dialyzed for 24 hours at $4{ }^{\circ} \mathrm{C}$ in cellulose tubes (Sigma, 12000 MWCO) against several aliquots of the same buffer.

The dialyzed fraction was loaded onto a column $(4 \mathrm{~cm} \times 20 \mathrm{~cm})$ containing DEAE-Sepharose CL-6B (Sigma-Aldrich) ionic exchange resin, washed with three volumes of phosphate buffer $0.025 \mathrm{M} \mathrm{pH} 7$ and eluted with a $\mathrm{KCl}$ gradient $0-0.5 \mathrm{M}(500 \mathrm{~mL})$ in the same buffer. The fractions were collected and analysed by means of UV-visible spectroscopy. The selected fractions were pooled and concentrated by ultrafiltration on Vivaspin 20 (Sartorius, $10000 \mathrm{MWCO}$ ). The final SBP sample was then stored at $-12{ }^{\circ} \mathrm{C}$ until use.

\section{Pentachlorophenol removal studies}

All the experiments were conducted at $30^{\circ} \mathrm{C}$ in an open glass beaker. SBP $\left(1.3 \times 10^{-9}-2.6 \times 10^{-9} \mathrm{M}\right)$ and, when needed, hydrogen peroxide (4-40 mg/L) and iron(II) $(4 \mathrm{mg} / \mathrm{L}$, added as sulphate salts) were added to $250 \mathrm{~mL}$ of a PCP solution $(1 \mathrm{mg} / \mathrm{L})$, kept in the dark and under stirring until use. The $\mathrm{pH}$ was adjusted to the desired value by dropwise addition of $\mathrm{HCl}$ or $\mathrm{NaOH}$ diluted solutions. A sample was withdrawn as reference 
before adding $\mathrm{H}_{2} \mathrm{O}_{2}$ to the PCP/SBP mixture. After the start of the reaction, $1 \mathrm{~mL}$ of reaction mixture was collected every 3 minutes up to 30 minutes and then every 30 minutes. Immediately, $1 \mathrm{~mL}$ of methanol was added to each sample in order to stop the reaction. The $\mathrm{pH}$ of the reaction mixture was measured before the start of the reaction and at the end.

The PCP concentration was determined by HPLC-UV analysis in a Perkin Elmer model Flexiar UPLC FX10). A Bronwnlee Analytical column (DB-C18) was employed as stationary phase. The elution was carried out with acetonitrile and formic acid $10 \mathrm{mM}(85: 15 \% \mathrm{v} / \mathrm{v})$ in a $0.3 \mathrm{~mL} / \mathrm{min}$ flow rate. The detector was set up at $215 \mathrm{~nm}$ and the results were expressed as $\mathrm{A} / \mathrm{A}_{0}$ vs reaction time, where $\mathrm{A}_{0}$ is the initial area of the PCP chromatographic peak and $\mathrm{A}$ is the corresponding area at each reaction time.

\section{Results and Discussion}

\subsection{SBP-based enzymatic process}

A first series of experiments were performed at $\mathrm{pH} 5$ to study the possibility of using the $\mathrm{SBP} / \mathrm{H}_{2} \mathrm{O}_{2}$ system to remove PCP from aqueous solutions. For this purpose, the behavior of a solution containing $1 \mathrm{mg} / \mathrm{L}$ of PCP $\left(3.75 \times 10^{-6} \mathrm{M}\right)$ and hydrogen peroxide $4 \mathrm{mg} / \mathrm{L}\left(1.17 \times 10^{-4} \mathrm{M}\right)$ was followed, both in absence and in the presence of SBP $\left(1.3 \times 10^{-9} \mathrm{M}\right)$. Figure 1 shows as $\mathrm{H}_{2} \mathrm{O}_{2}$ alone was not able to degrade PCP, while in the presence of the enzyme the reaction occurred, reaching a 35\% percent of PCP degradation in 30 min of reaction; beyond this point the reaction slowed down and in the subsequent 60 minutes only a further $5 \%$ of PCP degradation occurred. Similar results were obtained in the past for the degradation of PCP with free and immobilized horseradish peroxidase (J. Zhang et al. 2007). 


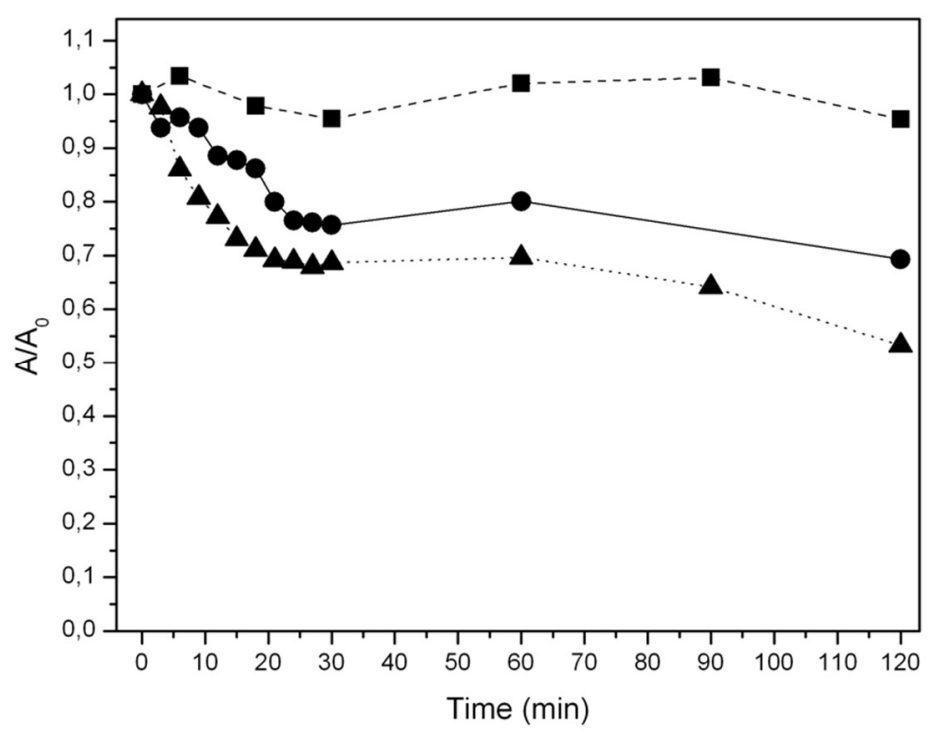

Fig 1. Degradation profiles of PCP $(1 \mathrm{mg} / \mathrm{L})$ vs. time under the following experimental conditions: (ם) 4 $\mathrm{mg} / \mathrm{L}$ of $\mathrm{H}_{2} \mathrm{O}_{2}$ without SBP, (A) $4 \mathrm{mg} / \mathrm{L}$ of $\mathrm{H}_{2} \mathrm{O}_{2}$ and $1.3 \cdot 10^{-9} \mathrm{M}$ of SBP and (-) $40 \mathrm{mg} / \mathrm{L}$ of $\mathrm{H}_{2} \mathrm{O}_{2}$ and $1.3 \cdot 10^{-9} \mathrm{M}$ of SBP

Moreover, the presence of higher amounts of $\mathrm{H}_{2} \mathrm{O}_{2}, 40 \mathrm{mg} / \mathrm{L}\left(1.17 \times 10^{-3} \mathrm{M}\right)$, did not result in an enhancement of the process. On the contrary, the results showed a similar time profile, but a slightly lower percentage of PCP degradation was reached (Figure 1). In fact, a detrimental effect of the excess of hydrogen peroxide, with a decrease in the enzyme activity, has been already observed for SBP (Wright and Nicell 1999) and can be attributed to an irreversible inhibition mechanism typical of heme-peroxidases, as extensively reviewed (Valderrama et al. 2002).

Some experiments were successively conducted in order to better understand the reasons of the incomplete degradation of PCP, even at low $\mathrm{H}_{2} \mathrm{O}_{2}$ concentration, and the extent of hydrogen peroxide inhibition. In these experiments the hydrogen peroxide concentration was halved $(2 \mathrm{mg} / \mathrm{L})$ or doubled $(8 \mathrm{mg} / \mathrm{L})$, but in the latter case $\mathrm{H}_{2} \mathrm{O}_{2}$ was added in two aliquots: the first at the start of the reaction and the second after 10 minutes (Figure 2). Moreover, also the concentrations of SBP and PCP were changed, and the corresponding results are shown in Figure 3. 


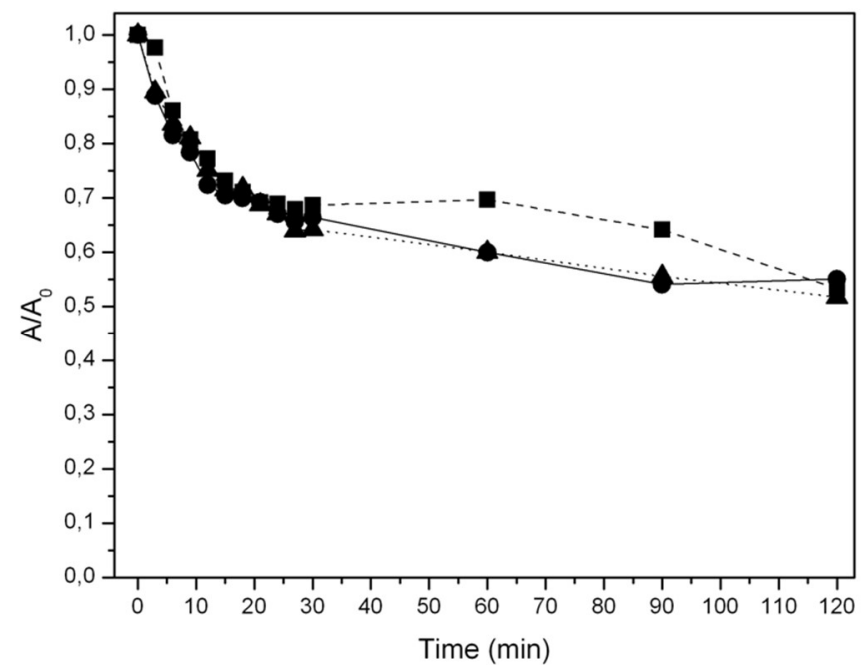

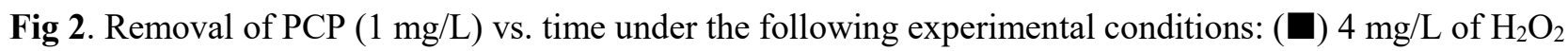
and $1.3 \times 10^{-9} \mathrm{M}$ of SBP - same data of Figure 1, reported for comparison, $(\mathbf{A})$ two successive additions of 4 $\mathrm{mg} / \mathrm{L}$ of $\mathrm{H}_{2} \mathrm{O}_{2}$ in the presence of $1.3 \cdot 10^{-9} \mathrm{M}$ of SBP and $\left(-2 \mathrm{mg} / \mathrm{L}\right.$ of $\mathrm{H}_{2} \mathrm{O}_{2}$ and $1.3 \times 10^{-9} \mathrm{M}$ of SBP

The strict similarity of the results obtained with 2, 4 and $8 \mathrm{mg} / \mathrm{L}$ of $\mathrm{H}_{2} \mathrm{O}_{2}$ concentrations (Figure 2) indicates that the inhibition due to hydrogen peroxide is relative unimportant in this range of concentrations and that it does not significantly affect the difficulty of achieving complete PCP degradation. On the other hand, the higher initial rate and percent of PCP removal obtained when the PCP concentration was reduced to 0.25 $\mathrm{mg} / \mathrm{L}$ (Figure 3) seems to highlight a role for PCP or its reaction products in the inhibition of the enzymatic action. 


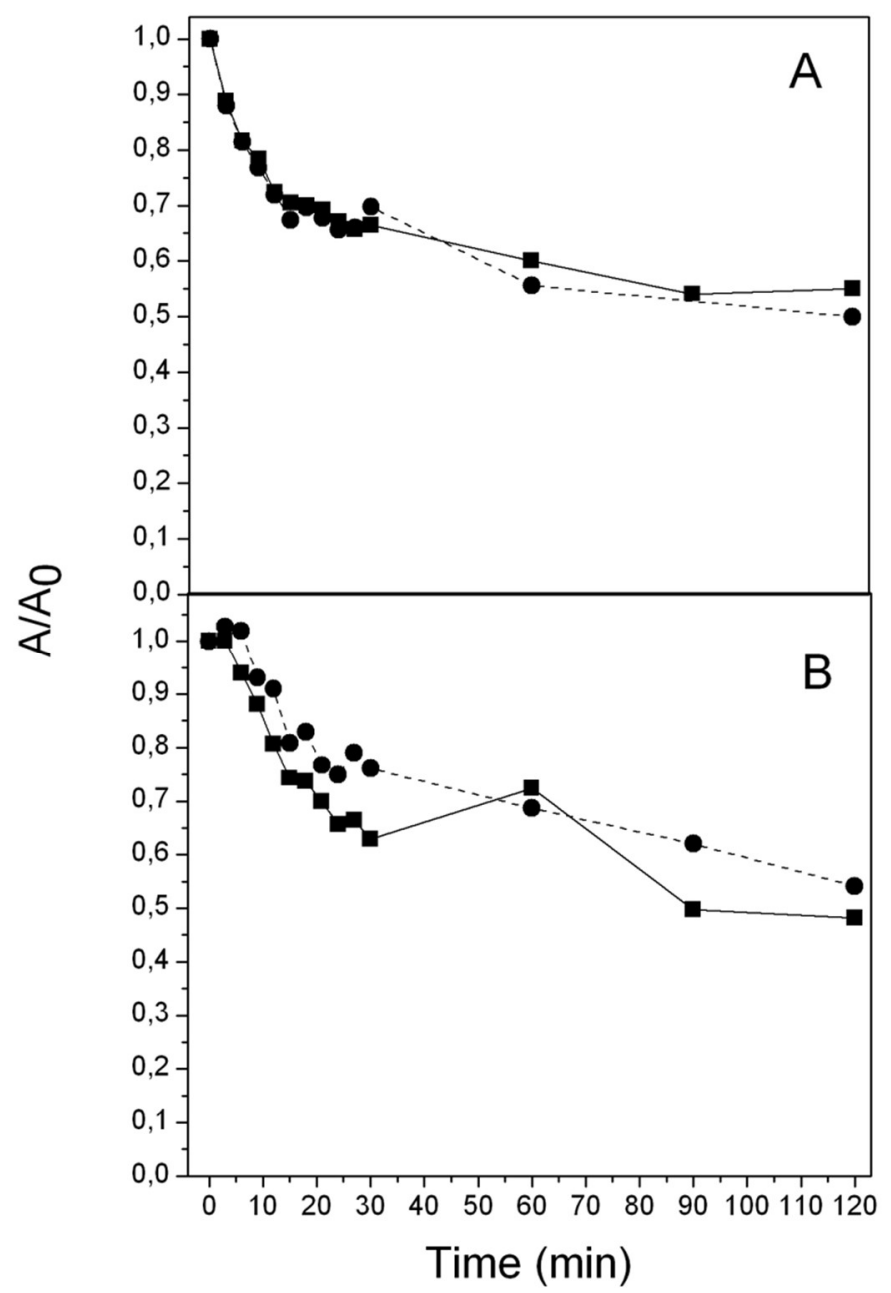

Fig 3. Degradation profiles of PCP vs. time under the following experimental conditions: A) $1 \mathrm{mg} / \mathrm{L}$ of PCP, $4 \mathrm{mg} / \mathrm{L}$ of $\mathrm{H}_{2} \mathrm{O}_{2}$ and two concentrations of SBP: $1.3 \times 10^{-9} \mathrm{M}(\mathbf{\square})$ and $2.6 \times 10^{-9} \mathrm{M}(\bullet)$; B) $4 \mathrm{mg} / \mathrm{L}$ of $\mathrm{H}_{2} \mathrm{O}_{2}$, $1.3 \times 10^{-9} \mathrm{M}$ of SBP and two concentrations of PCP: $1 \mathrm{mg} / \mathrm{L}(\mathbf{\square})$ and $0.25 \mathrm{mg} / \mathrm{L}$

Hence, the loss of efficiency of the reaction in these range of $\mathrm{H}_{2} \mathrm{O}_{2}$ concentrations could be instead attributed to the persistence of the reaction products into the catalytic site of SBP, which make progressively more difficult the access of new substrate molecules and slow down the catalytic process. This hypothesis is supported by the recognition, in similar experimental conditions, of both 2,3,5,6-tetrachloro-1,4benzoquinone and 2,2',3,3',5,5',6,6'-octachloro-1,1'-biphenyl-4,4'-diol as product of the PCP reaction catalyzed by horseradish peroxidase (Samokyszyn et al. 1995; G. Zhang and Nicell 2000).

\subsection{Evaluating the sinergetic effect of SBP and Fenton reaction}

Since in none of the previous experiments PCP removal was complete, an alternative approach was used. In particular, iron(II) ions were added to the reaction mixture in order to drive a Fenton process, induced by the presence of hydrogen peroxide, able to enhance the PCP removal. $4 \mathrm{mg} / \mathrm{L}$ of iron(II) were added as $\mathrm{FeSO}_{4}$ to 
$250 \mathrm{~mL}$ of solution containing $1 \mathrm{mg} / \mathrm{L}$ of PCP, $2.68 \times 10^{-9} \mathrm{M}$ of SBP and $4 \mathrm{mg} / \mathrm{L}$ of hydrogen peroxide. The experiments were carried out at $\mathrm{pH} 5$ and 6 and a control experiment without SBP was also performed at pH $=5$.

As shown in Figure 4, the Fenton reaction (in the absence of SBP) was able to remove $60-70 \%$ of PCP in the early stages of the process, but also in this case the PCP removal was not complete since iron inactivation by the formation of iron oxides or hydroxides stopped the reaction. Otherwise, in the presence of SBP, a clear synergetic effect was observed and a nearly complete elimination of PCP was reached in almost 1 hour when both SBP and iron(II) were present, even at $\mathrm{pH}$ as high as 6 . This might be due to a complementary effect of both processes: while the enzymatic reaction is efficient to degrade PCP, the presence of photo-Fenton prevents inhibitory effects on the enzyme of intermediates or $\mathrm{H}_{2} \mathrm{O}_{2}$.

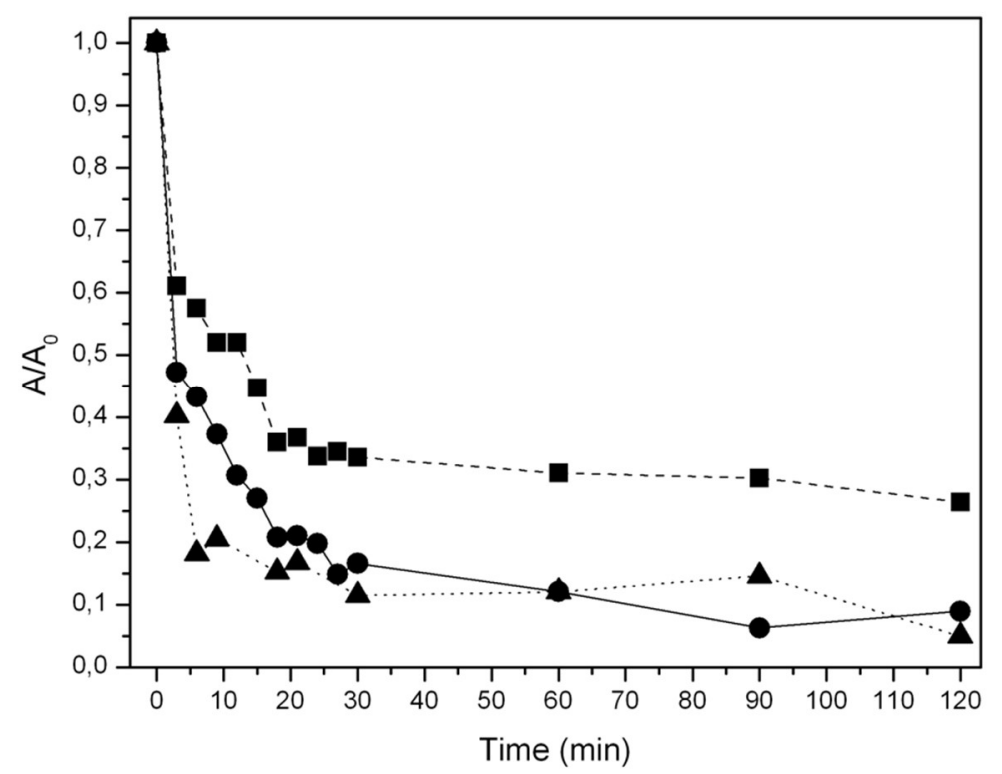

Fig 4. Progressive removal of PCP vs time in the presence of $4 \mathrm{mg} / \mathrm{L}$ of $\mathrm{Fe}(\mathrm{II}), 1 \mathrm{mg} / \mathrm{L}$ of PCP and $4 \mathrm{mg} / \mathrm{L}$ of $\mathrm{H}_{2} \mathrm{O}_{2}$ : () $2.68 \times 10^{-9} \mathrm{M}$ of SBP at $\mathrm{pH}=5,(\boldsymbol{\Delta}) 2.68 \times 10^{-9} \mathrm{M}$ of $\mathrm{SBP}$ at $\mathrm{pH}=6$, (口) without $\mathrm{SBP}$ at $\mathrm{pH}=5$

Finally, the reaction was also carried out in tap water in order to test the reaction system in conditions closer to natural matrices. The reaction was studied at pH 5, 6 and 7 and results are shown in Figure 5. At pH 7, PCP removal did not occur, while at pH 6 it was very limited (about 10\%). On the contrary, at pH 5 more than $50 \%$ of PCP was removed in 30 minutes, but the reaction did not proceed further and the PCP concentration remained the same even after 2 hours of reaction. 


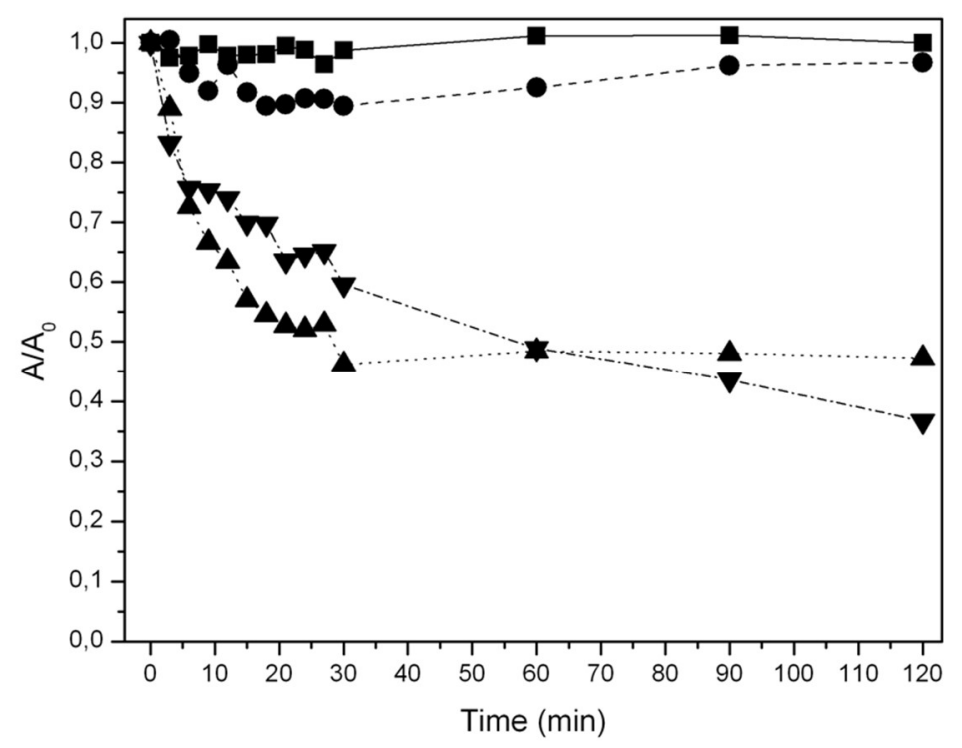

Fig 5. Removal of PCP vs time in tap water in the presence of $4 \mathrm{mg} / \mathrm{L}$ of Fe(II), $1 \mathrm{mg} / \mathrm{L}$ of PCP and $4 \mathrm{mg} / \mathrm{L}$

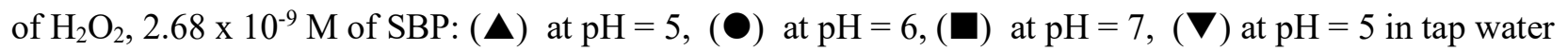
stirred overnight in an open vessel

We hypothesized that this result could be due to the scavenging effect of some ions (namely chloride and hydrogen carbonate) towards the reactive species involved in the Fenton reaction (Soler et al. 2009) and to the influence on the enzymatic process of the chlorine present in tap water. In order to clarify this point, tap water was left in an open vessel under magnetic stirring for one day to allow chlorine elimination. After this treatment, actually the reaction did not stop after 30 minutes, reaching $60 \%$ of PCP removal after 2 hours (Figure 5) and 70\% after 3 hours (data not shown).

\section{Conclusions}

The experimental results show as SBP could be able to remove PCP from aqueous solutions at slightly acidic $\mathrm{pH}$. But the progressive slowing down of the reaction rate, probably due to the interference of intermediates or reaction products, does not allow the complete removal of PCP.

The presence of iron salts allows overcoming this inconvenience, most probably due to the existence of a synergetic effect between Fenton and the enzymatic reaction, which results in a fast removal of the formed by-products. Nonetheless, this is not so efficient in tap water.

Hence further research is needed in this field in order to determine with other pollutants the real applicability of this approach and to remove the process inconveniences towards real application, in particular, in real aqueous matrices. 


\section{References}

Babuponnusami, A., \& Muthukumar, K. (2014). A review on Fenton and improvements to the Fenton process for wastewater treatment. Journal of Environmental Chemical Engineering, 2(1), 557-572. doi:10.1016/j.jece.2013.10.011

Ballschmiter, K. (2003). Pattern and sources of naturally produced organohalogens in the marine environment: biogenic formation of organohalogens. Chemosphere, 52(2), 313-324. doi:10.1016/S0045-6535(03)00211-X

Calza, P., Zacchigna, D., \& Laurenti, E. (2016). Degradation of orange dyes and carbamazepine by soybean peroxidase immobilized on silica monoliths and titanium dioxide. Environmental Science and Pollution Research, 23(23), 23742-23749. doi:10.1007/s11356-016-7399-1

Caza, N., Bewtra, J. ., Biswas, N., \& Taylor, K. . (1999). Removal of phenolic compounds from synthetic wastewater using soybean peroxidase. Water Research, 33(13), 3012-3018. doi:10.1016/S0043$1354(98) 00525-9$

Czaplicka, M. (2004). Sources and transformations of chlorophenols in the natural environment. Science of The Total Environment, 322(1-3), 21-39. doi:10.1016/j.scitotenv.2003.09.015

Donadelli, J. A., Carlos, L., Arques, A., \& García Einschlag, F. S. (2018). Kinetic and mechanistic analysis of azo dyes decolorization by ZVI-assisted Fenton systems: pH-dependent shift in the contributions of reductive and oxidative transformation pathways. Applied Catalysis B: Environmental, 231, 51-61. doi:10.1016/j.apcatb.2018.02.057

Durán, N., \& Esposito, E. (2000). Potential applications of oxidative enzymes and phenoloxidase-like compounds in wastewater and soil treatment: a review. Applied Catalysis B: Environmental, 28(2), 8399. doi:10.1016/S0926-3373(00)00168-5

Essam, T., Amin, M. A., El Tayeb, O., Mattiasson, B., \& Guieysse, B. (2007). Sequential photochemicalbiological degradation of chlorophenols. Chemosphere, 66(11), 2201-2209. doi:10.1016/j.chemosphere.2006.08.036

Garcia-Peña, E. I., Zarate-Segura, P., Guerra-Blanco, P., Poznyak, T., \& Chairez, I. (2012). Enhanced phenol and chlorinated phenols removal by combining ozonation and biodegradation. Water, Air, and Soil Pollution, 223(7), 4047-4064. doi:10.1007/s11270-012-1172-y 
Hoekstra, E. J., De Weerd, H., De Leer, E. W. B., \& Brinkman, U. A. T. (1999). Natural formation of chlorinated phenols, dibenzo-p-dioxins, and dibenzofurans in soil of a Douglas fir forest. Environmental Science and Technology, 33(15), 2543-2549. doi:10.1021/es9900104

Karci, A. (2014). Degradation of chlorophenols and alkylphenol ethoxylates, two representative textile chemicals, in water by advanced oxidation processes: The state of the art on transformation products and toxicity. Chemosphere, 99, 1-18. doi:10.1016/j.chemosphere.2013.10.034

Li, Z. (2018). Health risk characterization of maximum legal exposures for persistent organic pollutant (POP) pesticides in residential soil: An analysis. Journal of Environmental Management, 205, $163-$ 173. doi:10.1016/j.jenvman.2017.09.070

Marchis, T., Avetta, P., Bianco-Prevot, A., Fabbri, D., Viscardi, G., \& Laurenti, E. (2011). Oxidative degradation of Remazol Turquoise Blue G 133 by soybean peroxidase. Journal of Inorganic Biochemistry, 105(2), 321-327. doi:10.1016/j.jinorgbio.2010.11.009

Marchis, T., Cerrato, G., Magnacca, G., Crocellà, V., \& Laurenti, E. (2012). Immobilization of soybean peroxidase on aminopropyl glass beads: Structural and kinetic studies. Biochemical Engineering Journal, 67, 28-34. doi:10.1016/j.bej.2012.05.002

Muñoz, M., de Pedro, Z. M., Casas, J. A., \& Rodriguez, J. J. (2013). Chlorophenols breakdown by a sequential hydrodechlorination-oxidation treatment with a magnetic Pd-Fe/?-Al2O3 catalyst. Water Research, 47(9), 3070-3080. doi:10.1016/j.watres.2013.03.024

Naghdi, M., Taheran, M., Brar, S. K., Kermanshahi-pour, A., Verma, M., \& Surampalli, R. Y. (2018, March 1). Removal of pharmaceutical compounds in water and wastewater using fungal oxidoreductase enzymes. Environmental Pollution. Elsevier. doi:10.1016/j.envpol.2017.11.060

Ngo, T. T., \& Lenhoff, H. M. (1980). A sensitive and versatile chromogenic assay for peroxidase and peroxidase-coupled reactions. Analytical Biochemistry, 105(1), 389-397. doi:10.1016/00032697(80)90475-3

Olaniran, A. O., \& Igbinosa, E. O. (2011). Chlorophenols and other related derivatives of environmental concern: Properties, distribution and microbial degradation processes. Chemosphere, 83(10), $1297-$ 1306. doi:10.1016/j.chemosphere.2011.04.009

Oller, I., Malato, S., \& Sánchez-Pérez, J. A. (2011). Combination of Advanced Oxidation Processes and 
biological treatments for wastewater decontamination-A review. Science of The Total Environment, 409(20), 4141-4166. doi:10.1016/j.scitotenv.2010.08.061

Passardi, F., Cosio, C., Penel, C., \& Dunand, C. (2005, July 22). Peroxidases have more functions than a Swiss army knife. Plant Cell Reports. Springer-Verlag. doi:10.1007/s00299-005-0972-6

Pera-Titus, M., García-Molina, V., Baños, M. A., Giménez, J., \& Esplugas, S. (2004). Degradation of chlorophenols by means of advanced oxidation processes: a general review. Applied Catalysis B: Environmental, 47(4), 219-256. doi:10.1016/j.apcatb.2003.09.010

Qayyum, H., Maroof, H., \& Yasha, K. (2009). Remediation and treatment of organopollutants mediated by peroxidases: a review. Critical Reviews in Biotechnology, 29(2), 94-119. doi:10.1080/07388550802685306

Samokyszyn, V. M., Freeman, J. P., Rao Maddipati, K., \& Lloyd, R. V. (1995). Peroxidase-Catalyzed Oxidation of Pentachlorophenol. Chem. Res. Toxicol, 8, 349-355. http://pubs.acs.org/doi/pdf/10.1021/tx00045a005. Accessed 23 June 2017

Santos-Juanes, L., Amat, A. M., \& Arques, A. (2017). Strategies to Drive Photo-Fenton Process at Mild Conditions for the Removal of Xenobiotics from Aqueous Systems. Current Organic Chemistry, 21(12), 1074-1083. doi:10.1136/adc.2010.199901

Santos-Juanes, L., García Einschlag, F. S., Amat, A. M., \& Arques, A. (2017). Combining ZVI reduction with photo-Fenton process for the removal of persistent pollutants. Chemical Engineering Journal, 310, 484-490. doi:10.1016/j.cej.2016.04.114

Sarria, V., Parra, S., Adler, N., Péringer, P., Benitez, N., \& Pulgarin, C. (2002). Recent developments in the coupling of photoassisted and aerobic biological processes for the treatment of biorecalcitrant compounds. Catalysis Today, 76(2-4), 301-315. doi:10.1016/S0920-5861(02)00228-6

Sharma, S., Mukhopadhyay, M., \& Murthy, Z. V. P. (2013). Treatment of chlorophenols from wastewaters by Advanced Oxidation Processes. Separation \& Purification Reviews, 42(May 2015), 37-41. doi:10.1080/15422119.2012.669804

Soler, J., García-Ripoll, A., Hayek, N., Miró, P., Vicente, R., Arques, A., \& Amat, A. M. (2009). Effect of inorganic ions on the solar detoxification of water polluted with pesticides. Water Research, 43(18), 4441-4450. doi:10.1016/j.watres.2009.07.011 
Steevensz, A., Cordova Villegas, L. G., Feng, W., Taylor, K. E., Bewtra, J. K., \& Biswas, N. (2014). Soybean peroxidase for industrial wastewater treatment: a mini review. Journal of Environmental Engineering and Science, 9(3), 181-186. doi:10.1680/jees.13.00013

Sun, Z., Wei, X., Zhang, H., \& Hu, X. (2015). Dechlorination of pentachlorophenol (PCP) in aqueous solution on novel Pd-loaded electrode modified with PPy-SDBS composite film. Environmental Science and Pollution Research, 22(5), 3828-3837. doi:10.1007/s11356-014-3641-x

Tsai, W.-T. (2013). A review on environmental distributions and risk management of phenols pertaining to the endocrine disrupting chemicals in Taiwan. Toxicological \& Environmental Chemistry, 95(5), 723 736. doi:10.1080/02772248.2013.818150

Valderrama, B., Ayala, M., \& Vazquez-Duhalt, R. (2002, May 1). Suicide inactivation of peroxidases and the challenge of engineering more robust enzymes. Chemistry and Biology. Cell Press. doi:10.1016/S1074-5521(02)00149-7

Verbrugge, L. A., Kahn, L., \& Morton, J. M. (2018). Pentachlorophenol, polychlorinated dibenzo-p-dioxins and polychlorinated dibenzo furans in surface soil surrounding pentachlorophenol-treated utility poles on the Kenai National Wildlife Refuge, Alaska USA. Environmental Science and Pollution Research, 25(19), 19187-19195. doi:10.1007/s11356-018-2269-7

Wright, H., \& Nicell, J. A. (1999). Characterization of soybean peroxidase for the treatment of aqueous phenols. Bioresource Technology, 70(1), 69-79. doi:10.1016/S0960-8524(99)00007-3

Zhang, G., \& Nicell, J. A. (2000). Treatment of aqueous pentachlorophenol by horseradish peroxidase and hydrogen peroxide. Water Research, 34(5), 1629-1637. doi:10.1016/S0043-1354(99)00326-7

Zhang, J., Ye, P., Chen, S., \& Wang, W. (2007). Removal of pentachlorophenol by immobilized horseradish peroxidase. International Biodeterioration \& Biodegradation, 59, 307-314. doi:10.1016/j.ibiod.2006.09.003

Zheng, W., Yu, H., Wang, X., \& Qu, W. (2012, July 1). Systematic review of pentachlorophenol occurrence in the environment and in humans in China: Not a negligible health risk due to the re-emergence of schistosomiasis. Environment International. Pergamon. doi:10.1016/j.envint.2011.04.014 